\title{
Off-pump versus on-pump redo coronary artery bypass grafting: A propensity score analysis of long-term follow-up
}

Magdalena Iuliana Rufa, MD, ${ }^{\mathrm{a}}$ Adrian Ursulescu, MD, ${ }^{\mathrm{a}}$ Ragi Nagib, MD, ${ }^{\mathrm{a}}$ Selvaraj Shanmuganathan, MBBS, MD, FRCS, ${ }^{\mathrm{b}}$ Marc Albert, MD, ${ }^{\mathrm{a}}$ Stefan Reichert, MD, ${ }^{\mathrm{a}}$ and Ulrich F. W. Franke, MD, $\mathrm{PhD}^{\mathrm{a}}$

\section{ABSTRACT}

Objective: Redo coronary artery bypass grafting $(\mathrm{CABG})$ is associated with an increased early mortality reported up to $16 \%$. The aim of this study was to analyze the early and long-term results after redo CABG with special focus on the feasibility and safety of the off-pump technique in the setting of a high-volume off-pump CABG center.

Methods: From January 2006 to June 2015, isolated redo CABG was performed in 304 patients $(179=$ on-pump redo CABG, $125=$ off-pump redo CABG). We used propensity score matching with 14 preoperative variables to adjust for differences in baseline characteristics between the on-pump redo CABG and the offpump redo CABG groups. After 1:1 matching we selected 108 pairs for each group. Mean follow-up rate was 4.01 years.

Results: The final sample was $83.9 \%$ men $(n=225)$ with a mean age of $69.77 \pm 8$ years. After propensity score matching there was a significant difference in the total number of grafts performed in favor of on-pump redo CABG $(P=.011)$, whereas $66.7 \%$ (72 out of 108) of off-pump redo CABG patients received total arterial grafts. Off-pump redo CABG patients had a lower rate of postoperative renal failure necessitating dialysis $(4.6 \%$ vs $0 \% ; P=.06)$, required less recovery time in the intensive care unit $(1.33 \pm 1.03$ days vs $4.4 \pm 7.98$ days; $P<.001)$ and were discharged more quickly $(10.08 \pm 5.35$ days vs $14.1 \pm 10.6$ days; $P=.001$ ). Off-pump redo CABG led to better long-term survival (log-rank test, $P=.086$ ).

Conclusions: In our study, patients undergoing off-pump redo CABG had fewer postoperative complications, achieved faster recovery, and had better long-term survival. Hence, off-pump redo CABG is safe and feasible. (J Thorac Cardiovasc Surg 2020;159:447-56)

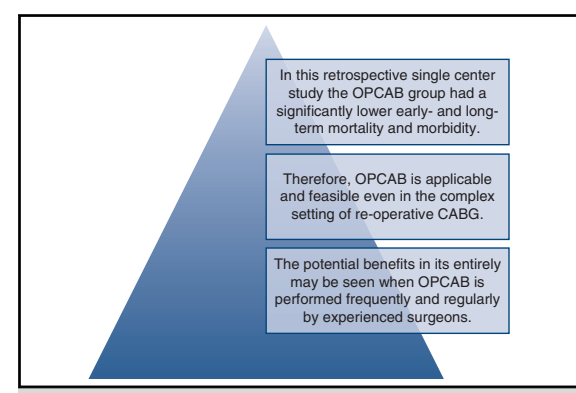

Resumed results, central message, and perspective statement.

\section{Central Message}

In our study, patients undergoing off-pump redo CABG had fewer postoperative complications, achieved faster recovery, and had better long-term survival. Off-pump redo CABG is safe and feasible.

\section{Perspective}

Although OPCAB is a technically challenging and a demanding procedure, it is applicable and feasible even in the most difficult circumstances. However, the entirety of potential benefits may be seen when OPCAB is performed frequently and regularly by experienced operators, even in this complex setting of reoperative CABG.

See Commentaries on pages 457 and 459.
From the a Department of Cardiovascular Surgery, Robert Bosch Hospital, Stuttgart, Germany; and ${ }^{b}$ Department of Cardiothoracic Surgery, Nottingham University Hospitals, National Health Service Trust, Nottingham, United Kingdom.

Read at the 98th Annual Meeting of The American Association for Thoracic Surgery, San Diego, California, April 28-May 1, 2018.

Received for publication April 27, 2018; revisions received March 15, 2019; accepted for publication March 26, 2019; available ahead of print June 20, 2019

Address for reprints: Magdalena Iuliana Rufa, MD, Department of Cardiovascular Surgery, Robert Bosch Hospital Stuttgart, Auerbachstraße 110, 70376, Stuttgart, Germany (E-mail: Magdalena.Rufa@rbk.de)

$0022-5223 / \$ 36.00$

Copyright (c) 2019 by The American Association for Thoracic Surgery

https://doi.org/10.1016/j.jtcvs.2019.03.122
Patients having undergone prior coronary artery bypass grafting $(\mathrm{CABG})$ and in those who are experiencing recurrent angina refractory to medical therapy with recurrent

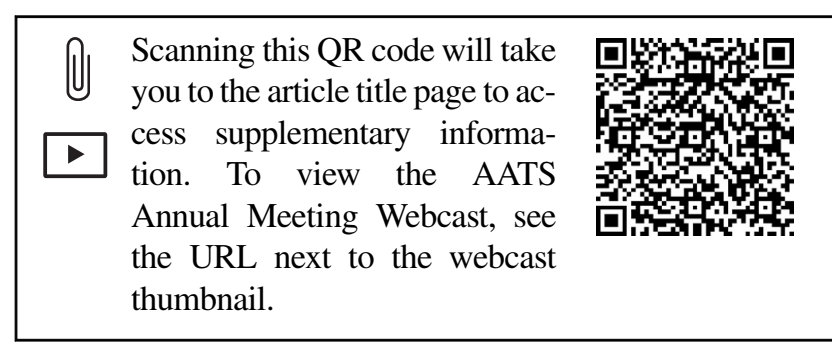




\section{Abbreviations and Acronyms \\ $\mathrm{CABG}=$ coronary artery bypass grafting \\ $\mathrm{CAD}=$ coronary artery disease \\ CORONARY $=$ Coronary Artery Bypass Graft Off or On Pump Revascularization Study \\ HLM = heart lung machine \\ LAD $\quad=$ left anterior descending \\ LITA $\quad=$ left internal thoracic artery \\ LVEF $\quad=$ left ventricular ejection fraction \\ OPCAB = off-pump coronary artery bypass \\ PS $\quad=$ propensity score \\ RITA $=$ right internal thoracic artery \\ $\mathrm{VD} \quad=$ vessel disease}

coronary disease are candidates for repeat interventional and/or surgical revascularization.

The great majority of patients operated on since the middle 1980s received a left internal thoracic artery (LITA) graft to the left anterior descending (LAD) coronary artery. This fact, combined with better management of saphenous vein conduits and improvement in antiplatelet and statin therapy, led to an increase in duration of the event-free period. Cardiac surgeons are nowadays faced with older patients with advanced and diffuse native vessel coronary artery disease (CAD), ${ }^{1}$ poorer left ventricular ejection fraction (LVEF), and more comorbidities who require coronary reoperations. ${ }^{2-4}$

When performing a redo CABG, a surgeon encounters many challenges: access to the heart with potential for cardiac injury during dissection, identification and management of patent grafts without harming them, availability of conduit material, embolization of atheromatous debris from venous grafts, and efficient myocardial protection.

Since 2007, when the minimally invasive coronary surgery program was implemented at our institution, we have achieved significant experience with off-pump coronary revascularization both in the primary and reoperative CABG settings. ${ }^{5}$ We decided to translate our off-pump coronary artery bypass $(\mathrm{OPCAB})$ experience to treat all patients undergoing coronary reoperation by a beating heart technique (Video 1 ).

In this study, we analyzed our early and long-term results after redo CABG with special focus on the feasibility and safety of the off-pump technique in redo CABG in a high-volume, off-pump CABG center.

\section{MATERIALS AND METHODS \\ Study Design}

During the period from January 2006 to June 2015, a total of 8441 patients underwent isolated CABG surgery at our institution. Of those,

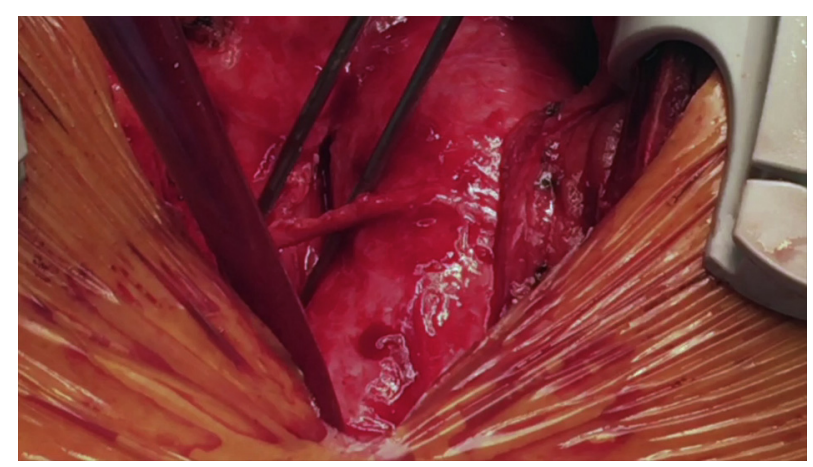

VIDEO 1. Redo CABG off-pump procedure. Anastomosis of a vein graft on the lateral wall followed by central anastomosis of the vein to the aorta under partial camping of the ascending aorta. Video available at: https:// www.jtcvs.org/article/S0022-5223(19)30971-7/fulltext.

we identified all patients who received isolated CABG at least 30 days after cardiac surgery. In the end, 304 patients were included in the study. We formed 2 groups according to the selected surgical technique, with or without the use of a heart-lung machine (HLM). The study was approved by our ethics review board and, due to the retrospective design and data collection from routine patient practice, patient approval was not considered mandatory.

\section{Patient Population}

More than $90 \%$ of the study population consisted of patients who were at their second cardiac surgery. Out of 304 patients, $269(88.5 \%)$ had undergone a previous $\mathrm{CABG}$ operation. The remaining 35 patients had either an isolated valve procedure (19 patients $[6.2 \%]$ ), a combined CABG and valve surgery (12 patients $[3.9 \%]$ ), or a corrective operation of a septum defect (4 patients [1.3\%]) as previous cardiac surgery.

One hundred twenty-five patients $(41.1 \%)$ were identified as having undergone redo off-pump surgery (off-pump redo CABG group). Twelve of them $(9.6 \%)$ underwent a minimally invasive direct coronary artery bypass procedure.

The remaining 179 patients $(58.9 \%$ ) were treated with the assist of an HLM (on-pump redo CABG). One hundred twenty-four of them $(69.2 \%)$ were revascularized under crossclamp and cardioplegic arrest and the other 55 patients $(30.7 \%)$ underwent procedure with an on-pump beating heart.

Nine patients $(2.9 \%)$ went on pump due to right ventricular injury secondary to dense adhesions (2 patients) or hemodynamic instability (7 patients). These conversions took place at the beginning of the surgery while the surgeon was freeing the heart from adhesions, so these patients were included in the redo on-pump group for final analysis.

\section{Definition of Variables}

The following data were included for analysis: demographic characteristics, extent of $\mathrm{CAD}$, comorbidities, preoperative risk factors, and urgency of surgery.

Impaired renal function was defined as stage $3 b$ or higher chronic kidney disease with a glomerular filtration rate $<45 \mathrm{~mL} / \mathrm{min} / 1.73 \mathrm{~m}^{2}$. According to the urgency of the procedure, the patients were divided into 3 categories: emergency (surgery should take place as soon as possible, in the following 6 hours), urgent (surgery should take place in the following 6-24 hours), and elective. The extent of the CAD was defined as 1,2, or 3 vessel disease (VD). Based on the preoperatively defined LVEF, patients were distributed into 3 categories: $<30 \%, 31 \%$ to $50 \%$, and $>50 \%$. 
TABLE 1. Unadjusted and adjusted baseline patient characteristics

\begin{tabular}{|c|c|c|c|c|c|c|c|}
\hline \multirow[b]{2}{*}{ Variable } & \multirow[b]{2}{*}{$\begin{array}{c}\text { Total } \\
\text { redo CABG } \\
(\mathbf{n}=\mathbf{3 0 4})\end{array}$} & \multirow[b]{2}{*}{$\begin{array}{c}\text { On-pump } \\
\text { redo CABG } \\
(\mathbf{n}=179)\end{array}$} & \multirow[b]{2}{*}{$\begin{array}{c}\text { Off-pump } \\
\text { redo CABG } \\
(n=125)\end{array}$} & \multicolumn{4}{|c|}{ Propensity score matching } \\
\hline & & & & $\begin{array}{c}\text { On-pump } \\
\text { redo CABG } \\
(\mathbf{n}=108)\end{array}$ & $\begin{array}{c}\text { Off-pump } \\
\text { redo CABG } \\
(\mathbf{n}=\mathbf{1 0 8})\end{array}$ & $\begin{array}{c}P \\
\text { value }\end{array}$ & SMD \\
\hline $\begin{array}{l}\text { Male } \\
\text { gender }\end{array}$ & $\begin{array}{l}255(83.9) \\
{[79.3-87.8]}\end{array}$ & $157(87.7)$ [82-92] & 98 (78.4) [70.2-85.3] & $90(83)$ [75-90] & $86(80)[71-87]$ & .6 & -0.0910 \\
\hline Age $(y)$ & $\begin{array}{c}69.77 \pm 8.02 \\
{[68.84-70.69]}\end{array}$ & $\begin{array}{c}69.06 \pm 7.75 \\
{[67.88-70.18]}\end{array}$ & $\begin{array}{l}70.8 \pm 8.31 \\
{[69.25-72.27]}\end{array}$ & $\begin{array}{l}71.05 \pm 5.86 \\
{[69.93-72.15]}\end{array}$ & $\begin{array}{c}71.29 \pm 7.39 \\
{[69.89-72.69]}\end{array}$ & .52 & 0.0308 \\
\hline BMI & $\begin{array}{c}27.86 \pm 3.85 \\
{[27.42-28.31]}\end{array}$ & $\begin{array}{c}28.05 \pm 3.74 \\
{[27.47-28.62]}\end{array}$ & $\begin{array}{r}27.58 \pm 3.99 \\
{[26.88-28.3]}\end{array}$ & $\begin{array}{c}27.85 \pm 3.22 \\
{[27.28-28.48]}\end{array}$ & $\begin{array}{c}27.48 \pm 3.91 \\
{[26.74-28.26]}\end{array}$ & .14 & -0.0940 \\
\hline $\begin{array}{l}\text { Type } 2 \\
\text { diabetes }\end{array}$ & $\begin{array}{l}108(35.5) \\
\quad[30.1-41.2]\end{array}$ & 68 (38) [30.9-45.5] & 40 (32) [23.9-40.9] & 39 (36) [27-46] & $32(30)$ [21-39] & .38 & -0.1395 \\
\hline $\begin{array}{l}\text { EuroSCORE I } \\
\text { additiv }\end{array}$ & $\begin{array}{c}9.26 \pm 3.85 \\
{[8.82-9.71]}\end{array}$ & $\begin{array}{c}9.23 \pm 4.09 \\
{[8.64-9.85]}\end{array}$ & $\begin{array}{c}9.31 \pm 3.92 \\
{[8.69-9.97]}\end{array}$ & $\begin{array}{c}8.8 \pm 3.52 \\
{[8.13-9.49]}\end{array}$ & $\begin{array}{c}9.21 \pm 3.2 \\
{[8.62-9.83]}\end{array}$ & .43 & \\
\hline COPD & $16(5.3)[3-8.4]$ & $10(5.6)[2.7-10]$ & $6(4.8)[1.8-10.2]$ & $7(6.5)$ [2.6-13] & $6(5.6)[2-12]$ & 1 & -0.0416 \\
\hline $\begin{array}{l}\text { Preoperative } \\
\text { creatinine } \\
\text { value }(\mathrm{mg} / \mathrm{dL})\end{array}$ & $\begin{array}{c}1.21 \pm 0.84 \\
{[1.12-1.32]}\end{array}$ & $1.2 \pm 0.84[1.1-1.35]$ & $\begin{array}{c}1.21 \pm 0.83 \\
{[1.08-1.38]}\end{array}$ & $\begin{array}{r}1.09 \pm 0.34 \\
{[1.03-1.16]}\end{array}$ & $\begin{array}{r}1.21 \pm 0.88 \\
{[1.07-1.4]}\end{array}$ & .75 & 0.1372 \\
\hline $\begin{array}{l}\text { Impaired } \\
\text { renal } \\
\text { function }\end{array}$ & $41(13.5)[9.9-17.8]$ & $20(11.2)[7-16.7]$ & $21(16.8)[10.7-24.5]$ & $12(11)[6-19]$ & $16(15)[9-23]$ & .54 & -0.0996 \\
\hline Dialysis & $6(2)[0.7-4.2]$ & $4(2.2)[0.6-5.6]$ & $2(1.6)[0.2-5.7]$ & $0(0)[0.0-3.4]$ & $2(1.9)[0.2-6.5]$ & .5 & 0.1417 \\
\hline $\begin{array}{c}\text { Peripheral } \\
\text { vascular } \\
\text { disease }\end{array}$ & 43 (14.1) [10.4-18.6] & $26(14.5)[9.7-20.6]$ & 17 (13.6) [8.1-20.9] & $9(8.3)$ [3.9-15] & $14(13)[7.3-21]$ & .38 & 0.1374 \\
\hline Carotid stenosis & 33 (10.9) [7.6-14.9] & 19 (10.6) [6.5-16.1] & 14 (11.2) [6.3-18.1] & 9 (8.3) [3.9-15] & $11(10)$ [5.2-17] & .82 & 0.0566 \\
\hline $\begin{array}{l}\text { Cerebrovascular } \\
\text { disease }\end{array}$ & $26(8.6)[5.7-12.3]$ & $12(6.7)[3.5-11.4]$ & 14 (11.2) [6.3-18.1] & $10(9.3)[4.5-16]$ & 12 (11) [5.9-19] & .82 & 0.0585 \\
\hline \multicolumn{8}{|l|}{ Extent of CAD } \\
\hline $1 \mathrm{VD}$ & $6(1.97)$ [0.7-4.2] & $0(0)[0-2]$ & $6(4.8)[1.78-10.2]$ & - & - & & \\
\hline $2 \mathrm{VD}$ & $27(8.88)[5.93-12.7]$ & $9(5.03)[2.32-9.33]$ & $18(14.4)[8.76-21.8]$ & 7 (6.48) [2.65-12.9] & 13 (12) [6.57-19.7] & .24 & -0.1526 \\
\hline $3 \mathrm{VD}$ & $271(89.1)$ [85.1-92.4] & 170 (95) [90.7-97.7] & $101(80.8)[72.8-87.3]$ & $101(93.5)[87.1-97.4]$ & 95 (88) [80.3-93.4] & & \\
\hline $\begin{array}{l}\text { Cardiogenic } \\
\text { shock at } \\
\text { presentation }\end{array}$ & 5 (1.6) [0.5-3.8] & $5(2.8)$ [0.9-6.4] & $0(0)$ [0-2.9] & - & - & - & \\
\hline
\end{tabular}

Acute myocardial infarction No $\quad 172(56.6)[50.8-62.2] \quad 95(5.31)[45.5-60.6] \quad 77(61.6)[52.5-70.2] \quad 65$ (60.7) [50.3-69.5] 65 (60.7) [50.3-69.5] $<48 \mathrm{~h} \quad 28(9.21)[6.21-13] \quad 21(11.7)[7.41-17.4] \quad 7(5.6)[2.28-11.2] \quad 8(7.48)[3.25-14.1] \quad 5(4.67)[1.52-10.5]$ $\begin{array}{llllllll}<21 \mathrm{~d} & 30(9.87)[6.76-13.8] & 16(8.94)[5.2-14.1] & 14(11.2)[6.26-18.1] & 11(10.3)[5.2-17.5] & 13(12.1)[6.57-19.7] & .86\end{array}$ $\begin{array}{lllllll}21-91 \mathrm{~d} & 8(2.63)[1.14-5.12] & 6(3.35)[1.24-7.15] & 2(1.6)[0.19-5.66] & 3(2.8)[0.57-7.9] & 2(1.87)[0.22-6.53]\end{array}$ $>91 \mathrm{~d} \quad 66(21.4)[16.9-26.4] \quad 40(22.3)[16.5-29.2] \quad 25(20)[13.4-28.1] \quad 20(18.7)[11.7-27.1] 23(21.5)[14-30]$

\begin{tabular}{|c|c|c|c|c|c|c|c|}
\hline \multicolumn{8}{|l|}{ LVEF (\%) } \\
\hline$>50$ & $198(65.1)[59.5-70.5]$ & 107 (59.8) [52.2-67] & $91(72.8)$ [64.1-80.4] & 75 (69.4) [59.8-77.9] & 78 (72.2) [62.8-80.4] & \multirow{3}{*}{.77} & \multirow{3}{*}{0.0625} \\
\hline $30-50$ & $90(29.6)[24.5-35.1]$ & $58(32.4)[25.6-39.8]$ & $32(25.6)[18.2-34.2]$ & 33 (30.6) [22.1-40.2] & $30(27.8)[19.6-37.2]$ & & \\
\hline$<30$ & $16(5.26)[3.04-8.41]$ & $14(7.82)[4.34-12.8]$ & $2(1.6)[0.19-5.66]$ & - & - & & \\
\hline \multicolumn{8}{|l|}{ Status } \\
\hline Elective & $210(69.1)$ [63.6-74.2] & $124(69.3)$ [62-75.9] & $86(68.8)$ [59.9-76.8] & 77 (71.3) [61.8-79.6] & 77 (71.3) [61.8-79.6] & \multirow{3}{*}{1} & \\
\hline Urgent & $80(26.3)[21.5-31.6]$ & $46(25.7)[19.5-32.8]$ & $34(27.2)$ [19.6-35.9] & $28(25.9)[18-35.2]$ & $27(25)[17.2-34.3]$ & & -0.0628 \\
\hline Emergency & 14 (4.6) $[2.54-7.61]$ & $9(5.03)[2.32-9.33]$ & 5 (4) [1.31-9.09] & $3(2.78)[0.57-7.9]$ & $4(3.71)[1-9.2]$ & & 0.0452 \\
\hline
\end{tabular}

Values are presented as $\mathrm{n}(\%)$ [95\% confidence interval] or mean \pm standard deviation [95\% confidence interval]. CABG, Coronary artery bypass grafting; SMD, standardized mean differences; $B M I$, body mass index; EuroSCORE, European system for cardiac operative risk evaluation; COPD, chronic pulmonary disease; $C A D$, coronary artery disease, $V D$, vascular disease; $L V E F$, left ventricular ejection fraction. 


\begin{tabular}{|c|c|c|c|c|}
\hline \multirow[b]{2}{*}{ Variable } & \multirow[b]{2}{*}{$\begin{array}{l}\text { Total redo CABG } \\
\quad(n=304)\end{array}$} & \multicolumn{2}{|c|}{$\begin{array}{l}\text { Propensity score matching } \\
\end{array}$} & \multirow[b]{2}{*}{$\begin{array}{c}P \\
\text { value }\end{array}$} \\
\hline & & $\begin{array}{l}\text { On-pump redo CABG } \\
(\mathbf{n}=108)\end{array}$ & $\begin{array}{c}\text { Off-pump redo CABG } \\
(\mathbf{n}=108)\end{array}$ & \\
\hline \multicolumn{5}{|l|}{ Distal anastomoses } \\
\hline 1 & $71(23.4)[18.7-28.5]$ & $16(14.8)[8.4-22.9]$ & $34(31.5)[22.9-41.1]$ & \\
\hline 2 & $129(42.4)[36.8-48.2]$ & $52(48.1)[38.4-58]$ & $47(43.5)[34-53.4]$ & .011 \\
\hline 3 & 80 (26.3) [21.5-31.6] & 29 (26.9) [18.8-36.2] & $24(22.2)[14.8-31.2]$ & \\
\hline 4 & $23(7.6)[4.86-11.1]$ & $10(9.26)[4.53-16.4]$ & 3 (2.78) [0.57-7.9] & \\
\hline 5 & $1(0.3)[0.0-1.82]$ & $1(0.92)[0.02-5.05]$ & $0(0)[0-3.36]$ & \\
\hline \multicolumn{5}{|l|}{ Number of grafts to the anterior wall } \\
\hline 0 & $76(25)[20.2-30.3]$ & $30(30.6)[22.1-40.2]$ & $25(23.1)[15.6-32.2]$ & .14 \\
\hline 1 & 217 (71.4) [65.9-76.4] & $74(68.5)[58.9-77.1]$ & 78 (72.2) [62.8-80.4] & \\
\hline 2 & $11(3.6)[1.82-6.38]$ & $1(0.9)[0.02-5.05]$ & $5(4.63)[1.52-10.5]$ & \\
\hline \multicolumn{5}{|l|}{ Number of grafts to the posterior wall } \\
\hline 0 & $143(47)[41.3-52.8]$ & 45 (41.7) [32.3-51.5] & $56(51.9)[42-61.6]$ & .17 \\
\hline 1 & $160(52.6)[46.9-58.4]$ & $62(57.4)$ [47.5-66.9] & $52(48.1)[38.4-58]$ & \\
\hline 2 & $1(0.3)[0-1.82]$ & $1(0.92)[0.02-5.05]$ & $0(0)[0-3.36]$ & \\
\hline \multicolumn{5}{|l|}{ Number of grafts to the lateral wall } \\
\hline 0 & $95(31.3)[26.1-36.8]$ & 16 (14.8) [8.71-22.9] & $53(49.1)$ [39.3-58.9] & \\
\hline 1 & 199 (65.6) [59.8-70.8] & 88 (81.5) [72.9-88.3] & $52(48.1)[38.4-58]$ & $<.001$ \\
\hline 2 & 9 (3) [1.36-5.55] & 3 (2.78) [0.57-7.9] & $3(2.78)[0.57-7.9]$ & \\
\hline 3 & $1(0.3)[0-1.82]$ & $1(0.92)[0.02-5.05]$ & $0(0)[0-3.36]$ & \\
\hline \multicolumn{5}{|l|}{ Number of arterial grafts } \\
\hline 0 & 53 (17.4) [13.3-22.2] & $24(22.2)[14.8-31.2]$ & $16(14.8)[8.71-22.9]$ & \\
\hline 1 & $122(40.1)$ [34.6-45.9] & 47 (43.5) [34-53.4] & $40(37)$ [27.9-46.9] & .18 \\
\hline 2 & $82(27)[22.1-32.3]$ & $22(20.4)[13.2-29.2]$ & $34(31.5)[22.9-41.1]$ & \\
\hline 3 & $40(13.2)[9.57-17.5]$ & $11(10.2)[5.2-17.5]$ & $16(14.8)[8.71-22.9]$ & \\
\hline 4 & 7 (2.3) [0.93-4.69] & 4 (3.7) [1.02-9.21] & $2(1.8)[0.22-6.53]$ & \\
\hline \multicolumn{5}{|l|}{ Number of venous grafts } \\
\hline 0 & $134(44.1)$ [38.4-49.9] & $31(28.7)[20.4-38.2]$ & $72(66.7)[56.9-75.4]$ & \\
\hline 1 & 115 (37.8) [32.4-43.5] & 47 (43.5) [34-53.4] & $25(23.1)[15.6-32.2]$ & $<.001$ \\
\hline 2 & 48 (15.8) [11.9-20.4] & $25(23.1)[15.6-32.2]$ & $10(9.26)[4.53-16.4]$ & \\
\hline 3 & $7(2.3)[0.93-4.69]$ & $5(4.6)[1.52-10.5]$ & $1(0.92)[0.02-5.05]$ & \\
\hline Use of LITA & $135(44.4)[38.7-50.2]$ & $45(42)[32-52]$ & $51(47)[38-57]$ & .49 \\
\hline Use of RITA & $176(57.9)[52.1-63.5]$ & $61(56)[47-66]$ & $62(57)[48-67]$ & 1 \\
\hline Use of radial artery & $38(12.5)[9-16.8]$ & $11(10)[5.2-17]$ & $14(13)[7.3-21]$ & .67 \\
\hline Use of SVG & $172(56.6)[50.8-62.2]$ & 79 (73) [64-81] & $36(33)[25-43]$ & $<.001$ \\
\hline Use of mechanical anastomosis system & 45 (14.8) [11-19.3] & $7(6.5)[2.6-13]$ & $28(26)[18-35]$ & $<.001$ \\
\hline Completeness of revascularization & $246(80.9)[76-85.2]$ & 83 (77) [68-84] & $93(86)$ [78-92] & .11 \\
\hline \multicolumn{5}{|l|}{ Graft dominance (arterial/venous) } \\
\hline Dominant arterial (arterial > venous) & $32(10.5)[7.31-14.5]$ & $11(10.2)[5.2-17.5]$ & 3 (2.78) [0.57-7.9] & \\
\hline Dominant venous (venous $>$ arterial) & $27(8.88)[5.93-12.7]$ & 13 (12) [6.57-19.7] & $5(4.63)[1.51-10.4]$ & \\
\hline Total arterial & 134 (44) [38.4-49.9] & $31(28.7)$ [20.4-38.2] & $72(66.7)[56.9-75.4]$ & $<.001$ \\
\hline Total venous & $52(17.1)[13-21.8]$ & $24(20.2)[14.8-31.2]$ & 15 (13.9) [7.99-21.9] & \\
\hline Equal (arterial = venous) & 59 (19.4) [15.1-24.3] & 29 (26.9) [18.8-36.2] & 13 (12) [6.57-19.7] & \\
\hline
\end{tabular}

Values are presented as $\mathrm{n}(\%)$ [95\% confidence interval] or mean \pm standard deviation [95\% confidence interval]. CABG, Coronary artery bypass grafting; LITA, left internal thoracic artery, RITA, right internal thoracic artery, $S V G$, saphenous vein graft.

Surgery data included number and type of grafts, revascularized areas of the heart (anterior, lateral, or posterior wall), and rate of completeness of revascularization. Completeness of revascularization was defined as number of distal anastomoses performed divided by the number of targeted graftable vessels with angiographically significant stenoses.
Postoperative inpatient data collected were 30-day mortality, neurologic events, perioperative myocardial infarction, bleeding, postoperative organ dysfunction, duration of intensive care stay, and hospitalization.

In addition, patients were contacted either in writing or by telephone, and asked about late-onset cardiac and neurologic complications and quality of life. The survival follow-up rate was $98 \%$. Concerning the 


\begin{tabular}{|c|c|c|c|c|}
\hline \multirow[b]{2}{*}{ Variable } & \multirow[b]{2}{*}{$\begin{array}{l}\text { Total redo CABG } \\
\quad(n=304)\end{array}$} & \multicolumn{2}{|c|}{$\begin{array}{l}\text { Propensity score matching } \\
\end{array}$} & \multirow[b]{2}{*}{$\begin{array}{c}P \\
\text { value }\end{array}$} \\
\hline & & $\begin{array}{l}\text { On-pump redo CABG } \\
(\mathrm{n}=108)\end{array}$ & $\begin{array}{c}\text { Off-pump redo CABG } \\
(\mathbf{n}=108)\end{array}$ & \\
\hline $\begin{array}{l}\text { Postoperative new onset renal } \\
\text { failure requiring dialysis }\end{array}$ & $13(4.3)[2.3-7.2]$ & $5(4.6)[1.5-10]$ & $0(0)[0-3.3]$ & .06 \\
\hline Postoperative stroke & $6(2)[0.7-4.2]$ & $2(1.9)[0.23-6.5]$ & $1(0.92)[0.02-5]$ & 1 \\
\hline Deep sternal wound infection & $19(6.2)[3.8-9.6]$ & 7 (6.5) [2.6-13] & $8(7.4)[3.3-14]$ & 1 \\
\hline Use of IABP & $29(9.5)[6.5-13.4]$ & $10(9.3)[4.5-16]$ & $3(2.8)[0.58-7.9]$ & .08 \\
\hline Use of ECMO & $3(1)[0.2-2.9]$ & $1(0.93)[0.02-5.1]$ & $0(0)[0-3.3]$ & 1 \\
\hline Postoperative CPR & $19(6.2)[3.8-9.6]$ & $2(1.9)[0.23-6.5]$ & $2(1.9)[0.23-6.5]$ & 1 \\
\hline Postoperative PCI & $1(0.3)[0-1.8]$ & $0(0)[0-3.3]$ & $0(0)[0-3.3]$ & - \\
\hline Reoperation for bleeding & $15(4.9)[2.8-8]$ & $4(3.7)[1-9.2]$ & $1(0.93)[0.02-5.1]$ & .37 \\
\hline Reoperation with bypass revision & $5(1.6)[0.5-3.8]$ & $2(1.9)[0.23-6.5]$ & $1(0.93)[0.02-5]$ & 1 \\
\hline Postoperative ventricular arrhythmia & $10(3.3)[1.6-6]$ & $2(1.9)[0.23-6.5]$ & $1(0.93)[0.02-5]$ & 1 \\
\hline Length of ICU stay (d) & $3.55 \pm 7.97[2.72-4.55]$ & $4.4 \pm 7.98[2.97-6.06]$ & $1.33 \pm 1.03[1.15-1.55]$ & $<.001$ \\
\hline Length of hospital stay (d) & $12.21 \pm 10.1[11.1-13.43]$ & $14.1 \pm 10.6[12.25-16.26]$ & $10.08 \pm 5.35[9.12-11.18]$ & .001 \\
\hline
\end{tabular}

Values are presented as n (\%) [95\% confidence interval] or mean \pm standard deviation $[95 \%$ confidence interval]. $C A B G$, Coronary artery bypass grafting; $I A B P$, intra-aortic balloon pump; $E C M O$, extracorporeal membrane oxygenation; $C P R$, cardiopulmonary resuscitation; $P C I$, percutaneous coronary intervention; $I C U$, intensive care unit.

late-onset cardiac and neurologic complications and quality of life, our enquiry reached a follow-up rate of only $67.8 \%$.

\section{Surgical Technique}

The selection of patients to receive either on-pump or off-pump redo CABG was by surgeon discretion at the time of the procedure. All surgeons who performed procedures for the study patients were highly experienced in both procedures. The factors influencing the surgeon's decision to perform the redo procedure on pump were worse hemodynamic status at presentation (5 patients with cardiogenic shock), reduced LVEF $(<30 \%)$ (16 patients [5.26\%]), intimate contact of the heart with the sternum shown in preoperative computed tomography scan images, and poor quality of distal coronary target vessels.

The on-pump and off-pump procedures were conducted in the already described manner. ${ }^{5}$ All previous bypass grafts were identified and dissected carefully. The entire heart was mobilized in all cases. When available, we harvested both internal thoracic arteries in a skeletonized manner. Radial artery and/or great saphenous vein conduits were harvested endoscopically using Vasoview 6 Pro or Vasoview Hemopro 2 endoscopic vessel harvesting equipment (Maquet Inc, Rastatt, Germany).

The right internal thoracic artery (RITA) was sewn in a T-shaped manner onto the LITA. The LITA was used for anastomosing the diagonal branches and the LAD, whereas the RITA was used to anastomose all other coronary arteries. If the LITA had been used and in situ (eg, LITA-LAD), then it was used as a donor graft for performing a composite T/Y graft between the patent LITA and a RITA or a radial artery. The anastomosis of the vein graft on the aorta was often performed using a mechanical anastomosis system PAS Port System (Cardica Inc, Redwood City, Calif) to avoid clamping the aorta and to minimize aortic manipulation.

Regardless of the operative techniques used, graft flows were measured and documented using VeriQ Doppler flow probes (Medistim, Oslo, Norway).

\section{Statistical Analysis}

The categorical variables are presented as absolute and relative frequencies and all continuous variables are presented as mean \pm standard deviation.
Wilcoxon signed-rank test was used in the intergroup comparison of quantitative variables. Pearson $\chi^{2}$ test was used in the comparison of qualitative data and $95 \%$ confidence intervals were calculated using nonparametric bootstrapping.

With an error probability $<5 \%(P<.05)$, the null hypothesis was discarded and the distribution of the examined data was considered to be significantly different.

The Kaplan-Meier curve was used to estimate the survival of patients. Differences between groups were determined using log-rank test.

After excluding patients who presented with cardiogenic shock and those with LVEF $<30 \%$ we performed a propensity score (PS) matching analysis 1:1 nearest neighbor matching using a logistic regression as described by Ho and colleagues. ${ }^{6}$ The defined matching criteria were age, gender, extent of $\mathrm{CAD}$, body mass index, preoperative creatinine value, history of type 2 diabetes, chronic obstructive pulmonary disease, impaired renal function, dialysis, peripheral vascular disease, carotid stenosis, cerebrovascular disease, LVEF, and urgency of surgery (ie, elective, urgent, or emergency). Balance of the 2 matched groups was evaluated by standardized mean differences in the matching variables. Usually a maximum standardized mean difference of 0.1 or even 0.15 is considered acceptable. In the end, we found and compared 108 pairs. After PS matching, outcome variables were compared using Wilcoxon test for numerical variables and $\chi^{2}$ test for categorical variables. To analyze data we employed the statistic program SPSS version 21.0 for Windows (SPSS Inc, Chicago, Ill, ) and the statistical computing environment $\mathrm{R}$ version 3.5.0 together with the package MatchIt version 3.0.2 (R Foundation for Statistical Computing, Vienna, Austria), for pairwise matching of cases.

\section{RESULTS}

The demographic and preoperative characteristics of the unadjusted and PS adjusted populations are presented in Table 1. Patients included in the study had a high mean additive European System for Cadiac Operative Risk Evaluation score of $9.26 \pm 3.85$. A total of $89.1 \%$ presented with $3 \mathrm{VD}$. A total of $30.9 \%$ of surgeries were urgent or emergency. 


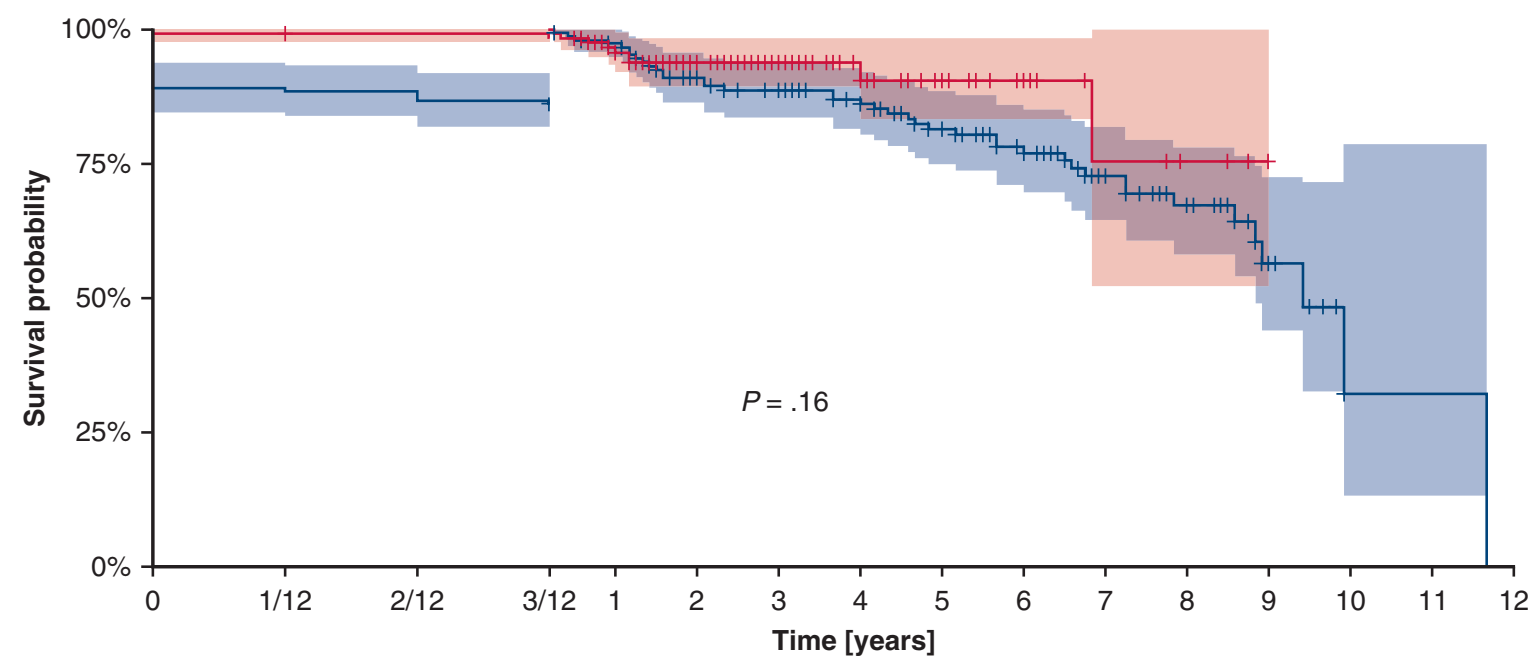

Number at risk

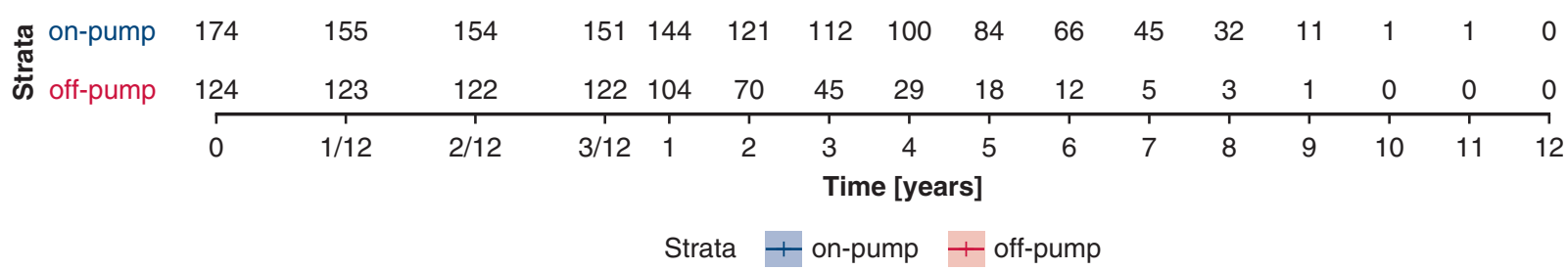

FIGURE 1. Kaplan-Meier survival curves for the unadjusted on-pump redo coronary artery bypass grafting (CABG) and off-pump redo CABG groups. The early results at 1 month, 2 months, and 3 months are expanded at the beginning of the curve, followed by a plot of conditional survival starting at $100 \%$ for the time after the first 3 months. The confidence limits of each group appear as a shaded area. The off-pump redo CABG group had a long-term survival rate.

In the unadjusted study groups, in the off-pump redo CABG subgroup there was a higher percentage of patients with impaired renal function, $(11.2 \%$ vs $16.8 \%)$ and of those with history of cerebrovascular disease $(6.7 \%$ vs $11.2 \%)$. The on-pump redo CABG group included a higher percentage of patients with 3 VD $(95 \%$ vs $80.8 \%$ ), patients presenting with cardiogenic shock $(2.8 \%$ vs $0 \%)$, a higher percentage of patients with recent myocardial infarction $(11.7 \%$ vs $5.6 \%)$ and also a significantly higher percentage of patients with LVEF $<30 \%(7.82 \%$ vs $1.6 \%)$.

After performing PS matching the differences in baseline characteristics between the 2 groups were completely even. Because in the on-pump group there were no patients with 1 VD, the PS matching analysis included only patients with 2 or 3 VD.

The PS adjusted operative data are shown in Table 2 and the PS-adjusted postoperative data are presented in detail in Table 3. On-pump redo CABG patients received a larger number of distal anastomoses $(P=.011)$ and more often bypasses to the posterior $(P=.17)$ and lateral wall $(P<.001)$. Patients in the off-pump redo CABG group received more often grafts to the anterior wall $(P=.14)$, fewer grafts using the saphenous vein $(P<.001)$, and reached a higher rate of total arterial revascularization $(28.7 \%$ vs $66.7 \% ; P<.001)$. The overall rate of completeness of revascularization was $81.4 \%$, with a higher percentage in favor of off-pump redo CABG group ( $77 \%$ vs $86 \% ; P=.11)$.

The patients in the unadjusted on-pump redo CABG group had higher rates of postoperative complications, as shown in Table E1. After PS matching the rate of postoperative complications was similar between the 2 study groups. Patients in the off-pump redo CABG group necessitated shorter intensive care unit and hospital stay.

The 30-day mortality rate in the overall study population was $6.6 \%$. The survival median follow-up time was 4.01 years for the unadjusted as well as the PS-adjusted population and was $98 \%$ complete.

As shown in the Kaplan-Meier survival curves for the 2 unmatched study groups (Figure 1), the survival rate was higher in the off-pump redo CABG group (log-rank test $P=.16$ ).

In Figure 2 are the Kaplan-Meier survival curves for the PS matching groups. The survival rate was higher in the off-pump redo $C A B G$ group, without reaching statistical significance (log-rank test $P=.086)$.

\section{DISCUSSION}

During the past 11 years, the working group at our institution has achieved excellent patient clinical outcome with regard to the adoption of minimally invasive cardiac surgery techniques. ${ }^{7-11}$ 

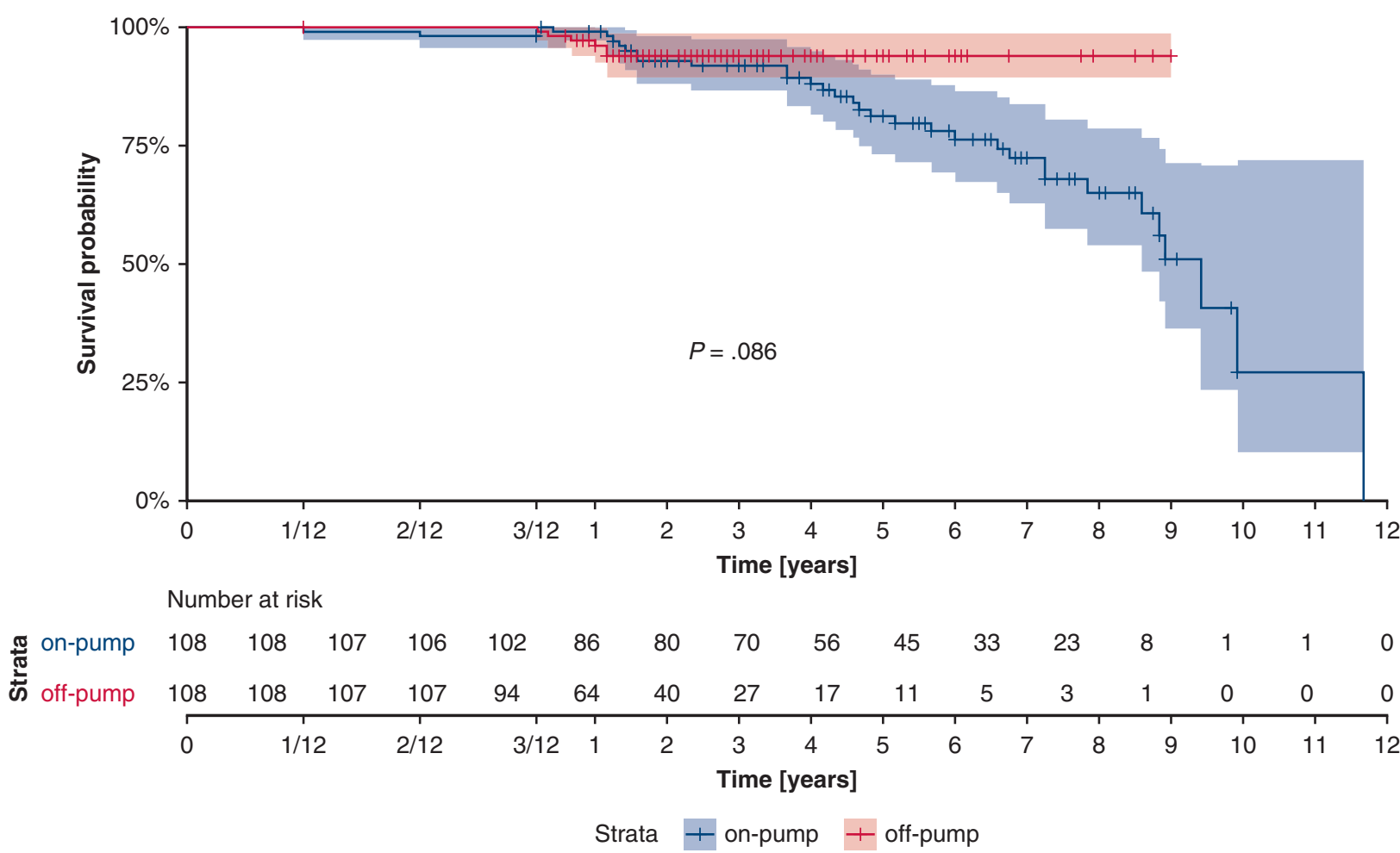

FIGURE 2. Kaplan-Meier survival curves for on-pump redo coronary artery bypass grafting (CABG) and off-pump redo CABG groups in the propensity score matched analysis. The early results at 1 month, 2 months, and 3 months are expanded at the beginning of the curve, followed by a plot of conditional survival starting at $100 \%$ for the time after the first 3 months. The confidence limits of each group appear as a shaded area. The off-pump redo CABG group had a long-term survival rate.

The continuous effort to innovate, adapt, improve clinical outcomes, and optimize patient care at our institution has led to a shift toward OPCAB in the treatment of patients undergoing $\mathrm{CABG}$, reaching an $88 \%$ of OPCAB operations in 2010 and continuously $\geq 90 \%$ since 2011 . The debate concerning possible benefits regarding postoperative morbidity and mortality that the off-pump technique may provide, as reported in early studies ${ }^{12-14}$ has been put to rest for now with the publication of the results from the Coronary Artery Bypass Graft Off or On Pump Revascularization Study (CORONARY) and German Off-Pump Coronary Artery Bypass in Elderly trial. ${ }^{15,16}$ In CORONARY, the rate of the composite outcome of death, stroke, myocardial infarction, renal failure, or repeat revascularization at 5 years of follow-up was similar among patients who underwent off-pump CABG and those who underwent on-pump CABG and there was no difference between the groups in quality of life measures. In the German Off-Pump Coronary Artery Bypass in Elderly trial, patients aged 75 years or older who underwent either elective first-time off-pump or on-pump CABG were included. The authors found within 30 days and within 12 months after surgery no difference between the 2 groups in the rate of the same composite outcome as defined for CORONARY.
However, in the European Society of Cardiology/ European Association for Cardio-Thoracic Surgery guidelines on myocardial revascularization published in $2014,{ }^{17}$ a percutaneous coronary intervention procedure is recommended for patients requiring repeat revascularization after a previous CABG procedure (class of recommendation: IIa, level of evidence: $\mathrm{C}$ ), rather than redo CABG. Nowadays we are faced with an yearly decrease in the overall number of isolated CABG surgeries and with an even more pronounced drop in the number of redo CABG procedures, most likely due to an increased number of percutaneous coronary intervention procedures performed in complex coronary cases. Under this premise, cardiac surgeons must perform less-invasive operations while delivering better results than with conventional surgery. As more patients become knowledgeable about minimally invasive surgery and request it, more health care providers will have to become skilled at offering these techniques.

In our study, groups after propensity matching there were no differences in the rate of postoperative complications. However, OPCAB patients had faster recovery and discharge, as well as better long-term survival, demonstrating the safety and efficacy of the procedure. 


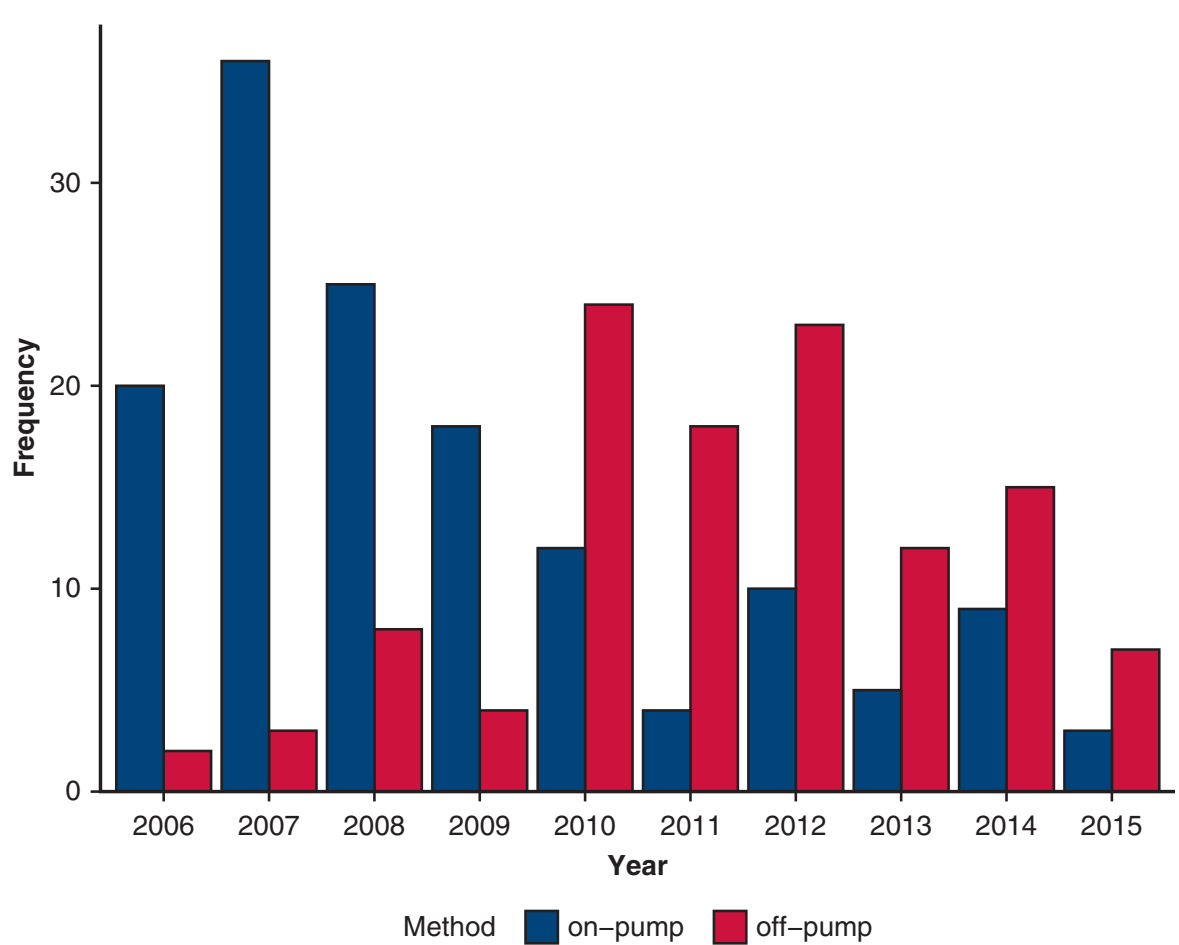

FIGURE 3. Bar graph depicting the evolution of redo coronary artery bypass grafting (redo CABG) at our institution over the study period between 2006 and 2015. The percentage of redo CABG performed by off-pump technique increased from $10 \%$ in 2006 to $72 \%$ in 2015 .

Other authors have compared off-pump redo CABG to onpump redo CABG. ${ }^{18-23}$ In all of those studies, there was a trend toward a reduction in mortality and morbidity in the redo off-pump groups. Dohi and colleagues ${ }^{18}$ reported a $13.6 \%(22.9 \%$ vs $9.3 \%)$ reduction in the composite 30 day mortality or major morbidity in the unadjusted study population and $10 \%$ reduction $(21.5 \%$ vs $11 \%)$ in the adjusted population after propensity matching, both in favor of off-pump redo CABG. Bruno and colleagues ${ }^{19}$ showed a reduction of the composite of in-hospital mortality, acute kidney injury, stroke, and severe low cardiac output requiring intra-aortic balloon pump in all of the 3 conducted analyses when OPCAB techniques were employed.

In general, complete revascularization is the goal. In most studies, the rate of incomplete revascularization is reported to be higher in the off-pump redo CABG group. ${ }^{19,20,24,25}$ and some have identified it as an independent risk factor for mortality. ${ }^{26}$ Incomplete revascularization has a negative influence on survival but longer HLM and surgical times can also have a negative influence on patient outcomes and recovery. In our study, OPCAB patients received fewer distal anastomoses, but had a higher rate of completeness of revascularization. This finding suggests that surgeons may be inclined to perform redo $\mathrm{OPCAB}$ on patients requiring fewer grafts, while considering on-pump for redo CABG in patients requiring more grafts. Spiliotopoulus and colleagues ${ }^{4}$ observed a reduction in the number of grafts performed at reoperation. They postulated that a higher number of bypassed vessels in the first operation and the subsequent reduced availability of graft material at reoperation can explain this finding.

In the unadjusted population, the overall 30-day mortality rate was $6.6 \%$, with 20 deaths, including 7 due to multiorgan failure/sepsis, 11 due to cardiogenic shock and global heart failure not responding to escalating therapy and support, and 2 due to stroke. For cause-and-effect considerations, the 20 patients experiencing early death also sustained the following postoperative complications: 6 cases of acute renal failure requiring dialysis, 6 cases needing re-exploration for bleeding, 2 cases of stroke, and 11 cases of low cardiac output of whom 10 received an intra-aortic balloon pump. In addition, the mean additive European system of cardiac risk evaluation score was $13.75 \pm 4.8$ and 9 of 20 patients presented $<48$ hours after the occurrence of an acute myocardial infarction.

In our analysis, the rate of new onset renal failure requiring dialysis was higher in the on-pump group. Zakkar and colleagues ${ }^{27}$ after investigating on 398 redo CABG patients, found an association between postoperative acute kidney injury and increased 30-day mortality and other major postoperative complications, as well as long-term mortality.

In most studies, the hospital mortality rate was reported to be lower in patients undergoing off-pump redo CABG. Dohi and colleagues ${ }^{18}$ report in the unadjusted population an overall 30-day mortality rate of $5.2 \%$, with $8.3 \%$ in the on-pump group and $3.1 \%$ in the off-pump group 


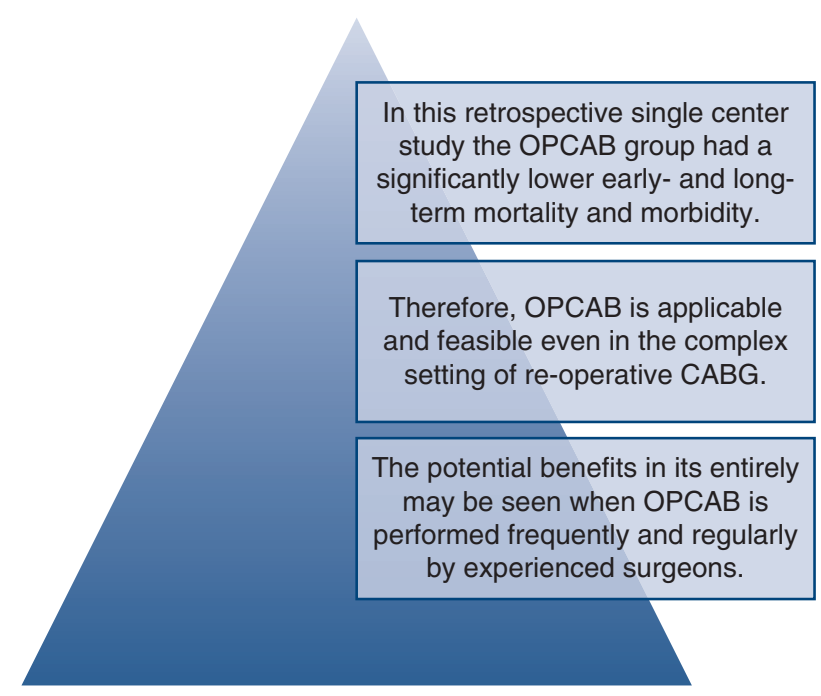

FIGURE 4. Graphical abstract including resumed results, central message, and perspective statement. $O P C A B$, Off-pump coronary artery bypass; $C A B G$, coronary artery bypass grafting.

$(P=.005)$. Yau and colleagues ${ }^{2}$ reported for their redo CABG population a 30 -day mortality rate of $6.8 \%$ and a $24 \%$ rate of low cardiac output syndrome with $16.1 \%$ of patients requiring the mechanical assistance of an IABP. Maltais and colleagues ${ }^{28}$ reported similar data in their redo CABG study population: $6 \%$ rate of in-hospital mortality and $20 \%$ rate of IABP application.

Bruno and colleagues ${ }^{19}$ found that in terms of 10-year survival redo OPCAB was as effective as conventional on-pump redo $\mathrm{CABG}$ across all of the 3 analyses undertaken. Our follow-up data support their finding, and also present a better survival profile for redo $\mathrm{OPCAB}$ patients.

Of the total of 304 redo CABG surgeries, 9 procedures were converted from off-pump to on-pump. The conversion took place early into the procedure, while still freeing the heart from adhesions and the patients were included in the on-pump group for final analysis. There were no early deaths or serious postoperative complications among these $9 \mathrm{pa}-$ tients. Two of them died during follow-up, at 2 and 4 years, respectively. These data support the theory that preemptive controlled conversion from off-pump to on-pump is not associated with higher in-hospital morbidity and mortality.

However, this is a nonrandomized retrospective study. A true comparison of off-pump redo $\mathrm{CABG}$ to on-pump redo CABG would require a randomized controlled trial, with well-defined selection criteria for both methods. Therefore, this study has several limitations. Due to the retrospective study design residual bias and unconsidered confounding factors may have contributed to our findings.

The study represents only a small cohort from a single institution of patients who were treated over a long period, thus possibly introducing confounding factors due to changes in clinical practice over time. Although there were minimal changes in the surgeon team at our institution, there was constant change in care paths; thus, the percentage of redo $\mathrm{CABG}$ performed by $\mathrm{OPCAB}$ technique increased from $10 \%$ in 2006 to $72 \%$ in 2015 . Figure 3 demonstrates the evolution of redo $\mathrm{CABG}$ at our institution during the study period with a decline in the total number of redo CABG per year (Figure 3). The concern of having treated a healthier population by OPCAB techniques more recently has no merit. Nowadays, we are confronted with an aging population presenting with a number of serious comorbidities who are in need of repeated medical care.

The original study groups included patients who were hemodynamically unstable and/or with highly reduced LVEF, all of whom were treated using the HLM. The PS matching analysis was conducted after having excluded these high-risk patients from the overall study cohort. It appears that the changes in operative approach across time are related to the difference in outcome despite propensity matching. Most studies include only patients who received elective procedures. In our study, more than $30 \%$ of patients underwent reoperation in an urgent or emergency setting and this could have influenced the higher 30-day mortality rate as well as the other observed outcomes. A more careful and maybe delayed surgical approach in these cases could lead to better results and reduced morbidity and mortality rates.

Another limitation to our study is that during follow-up we encountered the drawbacks inherent to any retrospective analysis. The described patient population was treated in an experienced, high-volume OPCAB center. Thus, our results may not apply to revascularization centers with low OPCAB application and acceptance. Off-pump redo CABG requires meticulous technique, patience, and experience (Figure 4).

\section{CONCLUSIONS}

In the setting of an experienced, high-volume OPCAB center, off-pump revascularization represents a valid and safe option for treatment of patients who require redo CABG. Improvements in surgical techniques permit surgeons today to extend the benefits of avoiding HLM for the majority of redo patients and achieving excellent results.

\section{Webcast}

You can watch a Webcast of this AATS meeting presentation by going to: https://www.jtcvs.org/article/S00225223(19)30971-7/fulltext.

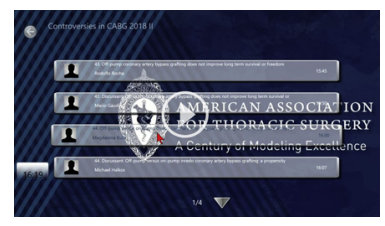




\section{Conflict of Interest Statement}

Authors have nothing to disclose with regard to commercial support.

The authors thank Jürgen Dippon, statistician at the Institute of Stochastics and Applications, University of Stuttgart.

\section{References}

1. Lytle BW, Tolis G Jr. Coronary artery reoperations. In: Cohn LH, Adams DH, eds. Cardiac Surgery in the Adult. 5th ed. New York: Mc Graw Hill Education; 2016:575-93.

2. Yau TM, Borger MA, Weisel RD, Ivanov J. The changing pattern of reoperative coronary surgery: trends in 1230 consecutive reoperations. J Thorac Cardiovasc Surg. 2000;120:156-63.

3. Ghanta RK, Kaneko TK, Gammie JS, Sheng S, Aranki SF. Evolving trends of reoperative coronary artery bypass grafting: an analysis of the Society of Thoracic surgeons adult cardiac surgery database. J Thorac Cardiovasc Surg. 2013;145:364-72.

4. Spiliotopoulos K, Maganti M, Brister S, Rao V. Changing pattern of reoperative coronary artery bypass grafting: a 20-year study. Ann Thorac Surg. 2011;92:40-7.

5. Usta E, Elkrinawi R, Ursulescu A, Nagib R, Mädge M, Salehi-Gilani S, et al. Clinical outcome and quality of life after reoperative CABG: off-pump versus on-pump—observational pilot study. J Cardiothorac Surg. 2013;8:66.

6. Ho DE, Imai K, King G, Stuart E. MatchIt: nonparametric preprocessing for parametric causal inference. J Stat Softw. 2011:42:1-28.

7. Franke UF, Ursulescu A, Göbel N, Nagib R, Hansen M, Yadav R, et al. Results and quality of life after minimally invasive Ross procedure. J Heart Valve Dis. 2015;24:295-301.

8. Franke UF, Albert M, Rustenbach C, Baumbach H. Minimally invasive Ross procedure through partial upper sternotomy. Interact Cardiovasc Thorac Surg. 2009:9:545-6.

9. Wachter K, Franke UF, Yadav R, Nagib R, Ursulescu A, Ahad S, et al. Feasibility and clinical outcome after minimally invasive valve-sparing aortic root replacement. Interact Cardiovasc Thorac Surg. 2017;24:377-83.

10. Baumbach H, Rustenbach CJ, Ahad S, Nagib R, Albert M, Ratge D, et al Minimally invasive extracorporeal bypass in minimally invasive heart valve operations: a prospective randomized trial. Ann Thorac Surg. 2016;102:93-100.

11. Goebel N, Bonte D, Salehi-Gilani S, Nagib R, Ursulescu A, Franke UFW Minimally invasive access aortic arch surgery. Innovations (Phila). 2017;12: $351-5$.

12. Puskas JD, Williams WH, Mahoney EM, Huber PR, Block PC, Duke PG, et al Off-pump vs conventional coronary artery bypass grafting: early and 1-year graft patency, cost, and quality-of-life outcomes: a randomized trial. JAMA. 2004;291: 1841-9.

13. Puskas JD, Kilgo PD, Lattouf OM, Thourani VH, Cooper WA, Vassiliades TA, et al. Off-pump coronary bypass provides reduced mortality and morbidity and equivalent 10-year survival. Ann Thorac Surg. 2008;86:1139-46.

14. Puskas JD, Williams WH, Duke PG, Staples JR, Glas KE, Marshall JJ, et al. Off-pump coronary artery bypass grafting provides complete revascularization with reduced myocardial injury, transfusion requirements, and length of stay: a prospective randomized comparison of two hundred unselected patients undergoing off-pump versus conventional coronary artery bypass grafting. J Thorac Cardiovasc Surg. 2003;125:797-808.
15. Lamy A, Devereaux PJ, Prabhakaran D, Taggart DP, Hu S, Straka Z, et al Five-year outcomes after off-pump or on-pump coronary-artery bypass grafting N Engl J Med. 2016;375:2359-68.

16. Diegeler A, Börgermann J, Kappert U, Breuer M, Böning A, Ursulescu A, et al. Off-pump versus on-pump coronary-artery bypass grafting in elderly patients N Engl J Med. 2013:368:1189-98.

17. Kolh P, Windecker S, Alfonso F, Collet JP, Cremer J, Falk V, et al. The task force on myocardial revascularization of the European Society of Cardiology (ESC) and the European Association for Cardio-Thoracic Surgery. (EACTS) 2014 ESC/EACTS Guidelines on myocardial revascularization. Eur J Cardiothorac Surg. 2014;46:517-92.

18. Dohi M, Miyata H, Doi K, Okawa K, Motomura N, Takamoto S, et al. The off-pump technique in redo coronary artery bypass grafting reduces mortality and major morbidities: propensity score analysis of data from the Japan cardiovascular surgery database. Eur J Cardiothorac Surg. 2015;47:299-308.

19. Bruno VD, Zakkar M, Rapetto F, Rathore A, Marsico R, Chivasso P, et al. Early health outcome and 10-year survival in patients undergoing redo coronary surgery with or without cardiopulmonary bypass: a propensity score-matched anal ysis. Eur J Cardiothorac Surg. 2017;52:945-51.

20. Kara I, Cakalagaoglu C, Ay Y, Al Salehi S, Yanartas M, Anasiz H, et al Reoperative coronary artery bypass surgery: the role of on-pump and off-pump techniques on factors affecting hospital mortality and morbidity. Ann Thorac Cardiovasc Surg. 2013;19:435-40.

21. Mishra YK, Collison SP, Malhotra R, Kohli V, Mehta Y, Trehan N. Tenyear experience with single-vessel and multivessel reoperative off-pump coronary artery bypass grafting. J Thorac Cardiovasc Surg. 2008;135: 527-32.

22. Morris CD, Puskas JD, Pusca SV, Lattouf OM, Cooper WA, Vassiliades TA, et al. Outcomes after off-pump reoperative coronary artery bypass grafting. Innovations (Phila). 2007:2:29-32

23. Vohra HA, Bahrami T, Farid S, Mafi A, Dreyfus G, Amrani M, et al Propensity score analysis of early and late outcome after redo off-pump and on-pump coronary artery bypass grafting. Eur J Cardiothorac Surg. 2008;33: $209-14$

24. Tugtekin SM, Alexiou K, Kappert U, Esche H, Joskowiak D, Knaut M, et al Coronary reoperation with and without cardiopulmonary bypass. Clin Res Cardiol. 2006;95:93-8.

25. Czerny M, Zimpfer D, Kilo J, Gottardi R, Dunkler D, Wolner E, et al. Coronary reoperations: recurrence of angina and clinical outcome with and without cardiopulmonary bypass. Ann Thorac Surg. 2003;75:847-52.

26. Di Mauro M, Iacò AL, Contini M, Teodori G, Vitolla G, Pano M, et al Reoperative coronary artery bypass grafting: analysis of early and late outcomes. Ann Thorac Surg. 2005;79:81-7.

27. Zakkar M, Bruno VD, Guida G, Angelini GD, Chivasso P, Suleiman MS, et al. Postoperative acute kidney injury defined by RIFLE criteria predict early health outcome and long-term survival in patients undergoing redo coronary artery bypass graft surgery. J Thorac Cardiovasc Surg. 2016;152 $235-42$

28. Maltais S, Widmer RJ, Bell MR, Daly RC, Dearani JA, Greason KL, et al. Reoperation for coronary artery bypass grafting surgery: outcomes and considerations for expanding interventional procedures. Ann Thorac Surg. 2016;103:1886-92.

Key Words: redo coronary artery bypass grafting, offpump redo $\mathrm{CABG}$, propensity score analysis 
TABLE E1. Unadjusted operative and postoperative outcomes

\begin{tabular}{|c|c|c|}
\hline Variable & On-pump redo CABG $(n=179)$ & Off-pump redo CABG $(n=125)$ \\
\hline \multicolumn{3}{|l|}{ Distal anastomoses } \\
\hline 1 & $26(14.5)[9.71-20.6]$ & 45 (36) [27.6-45.1] \\
\hline 2 & $80(44.7)[37.3-52.3]$ & 49 (39.2) [30.6-48.3] \\
\hline 3 & $52(29.1)[22.5-36.3]$ & $28(22.4)[15.4-30.7]$ \\
\hline 4 & 20 (11.2) [6.96-16.7] & $3(2.4)$ [0.49-6.85] \\
\hline 5 & $1(0.55)$ [0.01-3.07] & $0(0)[0-2.9]$ \\
\hline \multicolumn{3}{|l|}{ Number of grafts to the anterior wall } \\
\hline 0 & $45(25.1)[19-32.2]$ & $31(24.8)[17.5-33.3]$ \\
\hline 1 & 130 (72.6) [65.5-79] & 87 (69.6) [60.7-77.5] \\
\hline 2 & $4(2.23)[0.6-5.6]$ & 7 (5.6) [2.28-11.2] \\
\hline \multicolumn{3}{|l|}{ Number of grafts to the posterior wall } \\
\hline 0 & $76(42.5)[35.1-50.1]$ & 67 (53.6) [44.5-62.6] \\
\hline 1 & $102(57)[49.4-64.3]$ & $58(46.4)[37.4-55.5]$ \\
\hline 2 & $1(0.55)$ [0.01-3.07] & $0(0)[0-2.9]$ \\
\hline \multicolumn{3}{|l|}{ Number of grafts to the lateral wall } \\
\hline 0 & $30(16.8)[11.6-23.1]$ & $65(52)[42.9-61]$ \\
\hline 1 & $143(79.9)[73.3-85.5]$ & $56(44.8)[35.9-54]$ \\
\hline 2 & 5 (2.79) [0.91-6.4] & $4(3.2)[0.87-7.99]$ \\
\hline 3 & $1(0.55)[0.01-3.07]$ & $0(0)[0-2.9]$ \\
\hline \multicolumn{3}{|l|}{ Number of arterial grafts } \\
\hline 0 & 35 (19.6) [14-26.1] & 18 (14.4) [8.76-21.8] \\
\hline 1 & $71(39.7)[32.4-47.2]$ & $51(40.8)[32.1-49.9]$ \\
\hline 2 & $46(25.7)[19.5-32.8]$ & $36(28.8)[21.1-37.6]$ \\
\hline 3 & $22(12.3)[7.87-18]$ & $18(14.4)[8.76-21.8]$ \\
\hline 4 & 5 (2.79) [0.9-6.4] & $2(1.6)[0.19-5.66]$ \\
\hline \multicolumn{3}{|l|}{ Number of venous grafts } \\
\hline 0 & 49 (27.4) [21-34.5] & $85(68)[59.1-76.1]$ \\
\hline 1 & 88 (49.2) [41.6-56.7] & 27 (21.6) [14.7-29.8] \\
\hline 2 & $36(20.1)[14.5-26.7]$ & $12(9.6)[5.06-16.2]$ \\
\hline 3 & $6(3.35)[1.24-7.15]$ & $1(0.8)[0.02-4.38]$ \\
\hline Use of LITA & $76(42)[35-50]$ & 59 (47) [38-56] \\
\hline Use of RITA & $107(60)[52-67]$ & $69(55)[46-64]$ \\
\hline Use of radial artery & $22(12)[7.9-18]$ & $16(13)[7.5-21]$ \\
\hline Use of SVG & $132(74)[67-80]$ & $40(32)[24-41]$ \\
\hline Use of mechanical anastomosis system & $13(7.3)[3.9-12]$ & $32(26)[18-34]$ \\
\hline Completeness of revascularization & $139(78)[71-84]$ & $107(86)[78-91]$ \\
\hline \multicolumn{3}{|l|}{ Graft dominance (arterial/venous) } \\
\hline Dominant arterial (arterial > venous) & $29(16.2)[11.1-22.4]$ & $3(2.4)[0.49-6.8]$ \\
\hline Dominant venous (venous $>$ arterial) & 20 (11.2) [6.96-16.7] & 7 (5.6) [2.28-11.2] \\
\hline Total arterial & 49 (27.4) [21-34.5] & $85(68)[59.1-76.1]$ \\
\hline Total venous & 35 (19.6) [14-26.1] & 17 (13.6) [8.13-20.9] \\
\hline Equal (arterial $=$ venous) & $46(25.7)[19.5-32.8]$ & $13(10.4)[5.65 .-17.1]$ \\
\hline Postoperative new-onset renal failure requiring dialysis & $13(7.3)[3.9-12]$ & $0(0)[0-2.9]$ \\
\hline Postoperative stroke & $4(2.2)[0.61-5.6]$ & $2(1.6)[0.19-5.7]$ \\
\hline Deep sternal wound infection & $10(5.6)[2.7-10]$ & $9(7.2)[3.3-13]$ \\
\hline Use of IABP & $26(15)[9.7-21]$ & $3(2.4)[0.5-6.9]$ \\
\hline Use of ECMO & $3(1.7)[0.35-4.8]$ & $0(0)[0-2.9]$ \\
\hline Postoperative CPR & $17(19.5)[5.6-15]$ & $2(1.6)[0.19-5.7]$ \\
\hline Postoperative PCI & $1(0.56)[0.01-3.1]$ & $0(0)[0-2.9]$ \\
\hline
\end{tabular}


TABLE E1. Continued

Variable

Reoperation for bleeding

Reoperation with bypass revision

Postoperative ventricular arrhythmia

Length of ICU stay (d)

Length of hospital stay (d)

Values are presented as n (\%) [95\% confidence interval] or mean \pm standard deviation $[95 \%$ confidence interval]. CABG, Coronary artery bypass grafting; $L I T A$, left internal thoracic artery; RITA, right internal thoracic artery; $S V G$, saphenous vein graft; IABP, intra-aortic balloon pump; $E C M O$, extracorporeal membrane oxygenation; $C P R$, cardiopulmonary resuscitation; $P C I$, percutaneous coronary intervention; $I C U$, intensive care unit.
On-pump redo CABG $(\mathbf{n}=\mathbf{1 7 9})$

Off-pump redo CABG $(n=125)$

13 (7.3) [3.9-12]
2 (1.6) [0.19-5.7] $1(0.8)[0-4.4]$

4 (2.2) [0.61-5.6] 2 (1.6) [0.19-5.7]

8 (4.5) [1.9-8.6]

$1.44 \pm 1.33[1.22-1.7]$

$5.02 \pm 10.1[3.62-6.63]$ $10.2 \pm 5.67[9.24-11.29]$

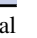

